TRABAJOS DE PREHISTORIA

66, N. ${ }^{\circ} 1$, enero-junio 2009, pp. 27-46, ISSN: 0082-5638

doi: $10.3989 /$ tp.2009.09011

\title{
El utillaje óseo musteriense del nivel " $D$ " de Axlor (Dima, Vizcaya): análisis de la cadena operativa
}

\author{
Mousterian bone tools from "D" level in Axlor (Dima, Vizcaya): operational sequence \\ analysis
}

Millán Mozota Holgueras $(*)$

\section{RESUMEN}

Este artículo presenta el análisis de 150 retocadores en esquirlas diafisiarias de huesos largos de las extremidades de grandes ungulados. Provienen del nivel D de Axlor (Dima, Vizcaya), datado en el final del Musteriense (hacia $44000 \mathrm{BP}$ ), y caracterizado por la abundancia de raederas Quina. El trabajo combina varios enfoques (tafonómico, tecnológico, traceológico y experimental) que se integran en una estructura de análisis de la cadena operativa. Se discute el papel de las llamadas industrias "poco elaboradas" en los modelos sobre las incapacidades de los neandertales, y su potencial informativo sobre las sociedades del Paleolítico medio.

\begin{abstract}
This paper presents the analysis of 150 retouching tools. They are diaphisis bone splinters from the long limb bones of ungulates. They were found in level " $D$ " at Axlor (Dima, Vizcaya), which corresponds to the last stages of Mousterian period (about 44000 BP). This level contains an abundance of Quina-type side scrapers. The study combines different approaches (taphonomy, technology, traceology and experimentation) within an structure of operational sequence analysis. The role of "sparsely elaborated" tools in neanderthals disability models, and their informative potential about Middle Palaeolithic societies, are discused.
\end{abstract}

Palabras clave: Retocadores; Cadena operativa; Tafonomía; Tecnología; Traceología; Experimentación; Musteriense; Neandertales; Paleolítico Medio; Axlor; País Vasco.

Key words: Retouching tools; Operational sequence; Taphonomy; Technology; Traceology; Experimental;

(*) Instituto Internacional de Investigaciones Prehistóricas de Cantabria. Facultad de Filosofía y Letras, Ed. Interfacultativo. Universidad de Cantabria. Av/ Los Castros s/n. 39005 Santander. Correo electrónico: millanm@ono.com

Recibido: 16-VII-2008; aceptado: 20-II-2009.
Mousterian; Neanderthals; Middle Palaeolithic; Axlor; Basque Country.

\section{INTRODUCCIÓN}

El utillaje en hueso del Paleolítico medio, a menudo denominado "poco elaborado", apenas ha sido estudiado en su papel tecnológico, social y económico. La constatación de que determinados útiles (los retocadores de hueso) tienen una presencia importante en los yacimientos musterienses (Armand y Delagnes 1998; Patou-Mathis 2002; Beauval 2004), y otras evidencias de trabajo y utilización del hueso, en un marco tecnológico (Gaudzinski 1999), hacen necesaria una revisión del concepto y del papel de estas industrias "poco elaboradas" en la interpretación de las sociedades del Paleolítico medio europeo.

Los retocadores en hueso son un útil característico del Paleolítico medio de toda Europa, y también están presentes en otros ámbitos geográficos (Henshilwood et al. 2001; Boeda et al. 1998) y cronológicos (Tinnes 2001). Por lo general, se trata de fragmentos espesos de diáfisis de grandes ungulados, de longitud variable, y perfil plano-convexo. Presentan una o varias zonas de uso, caracterizadas por la acumulación de impresiones lineales y estrías. Esas huellas (y otros estigmas, como se expone en este trabajo) son producto de su uso en la gestión de la industria lítica.

\subsection{Los retocadores de hueso del Paleolítico medio en el marco regional}

Para una breve contextualización del conjunto presentado, se ofrece una relación de yacimientos que han librado utillaje óseo de cronología de $\mathrm{Pa}$ - 
leolítico medio, en el entorno regional (sensu lato) del yacimiento de Axlor (Fig. 1).

a) Cantábrico central: en Cueva Morín (Villanueva de Villaescusa, Cantabria), excavada en los años sesenta, se señaló la presencia de útiles de hueso, en el nivel 17 (Freeman 1971). Estos materiales fueron criticados (Binford 1983; Straus 1992) por ser considerados como un conjunto de pseudoartefactos. Sin embargo, en la publicación sobre Cueva Morín (Freeman 1971) se recogen 63 huesos, descritos como fragmentos de diáfisis con "machacamientos" en los extremos. Dichos materiales (de las excavaciones originales de Freeman y Echegaray) son de cronología musteriense, y se hallan en proceso de estudio por nuestra parte. En ese sentido, se han identificado varios retocadores entre los materiales del nivel 17, que pueden corresponderse con los descritos por Freeman. Asimismo se han localizado otros retocadores óseos entre los materiales de los niveles 14 y 15, también de cronología de Paleolítico medio. Por otro lado, en Covalejos (Piélagos, Cantabria) se ha citado (Sanguino y Montes 2005) la presencia de retocadores en hueso en los niveles musterienses, junto con otros hallazgos de "huesos retocados".

b) Cantábrico oriental: en los trabajos originales de J.M. de Barandiarán sobre Axlor, se cita la presencia de utillaje en hueso (Barandiarán 1980), después discutido por Martínez-Moreno (2005/2006), quien desestima la mayor parte de los posibles artefactos, como producto de la frag-

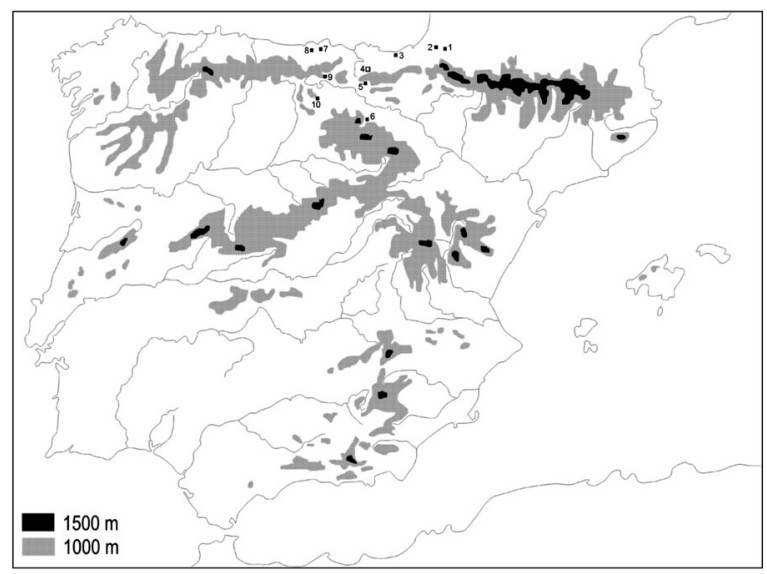

Fig. 1. Yacimientos musterienses peninsulares y del Suroeste de Francia citados en el texto: 1. Isturitz; 2. Olha I; 3. Amalda; 4. Axlor; 5. Arrillor; 6. Peña Miel; 7. Morín; 8. Covalejos; 9. Prado Vargas; 10. Valdegoba. mentación del hueso para obtener la médula, y también señala la presencia de retocadores en hueso. El yacimiento de Arrillor también ha librado retocadores en hueso, en sus niveles de $\mathrm{Pa}$ leolítico medio (Bermúdez de Castro y Sanz de Buruaga 1999). En el yacimiento de Amalda, excavado por J. Altuna et al. (1990) hemos detectado un pequeño conjunto de retocadores, entre los restos de fauna musterienses, que están en proceso de estudio por nuestra parte.

Ya en el sur de Francia, en el Departamento de Pirineos-Atlánticos, Passemard señaló la presencia de fragmentos de diáfisis con impresiones en Isturitz (Passemard 1922) y Olha I (Passemard 1924). Los materiales musterienses de Isturitz fueron revisados en un trabajo posterior (Leroy-Prost 1974) quien los denomina "compresores".

c) Alto Valle del Ebro y noreste de la Meseta: en el nivel $\mathrm{G}$ (Musteriense) del yacimiento de Peña Miel, se halló un nutrido conjunto de retocadores en hueso, estudiados en detalle y publicados como parte de la monografía del yacimiento (Barandiarán 1987). En el norte de Burgos, se ha citado la presencia de retocadores en hueso en los conjuntos musterienses de Valdegoba y Prado Vargas (Díez Fernández-Lomana y Navazo 2005).

\subsection{El yacimiento de Axlor}

Este trabajo presenta los resultados de un estudio sobre el utillaje óseo del nivel D de Axlor (Dima, Vizcaya). La cueva de Axlor se encuentra situada en el barrio de Indusi, en una zona abrupta y de roquedo, a $320 \mathrm{~m}$ s.n.m. Aunque durante buena parte de su historia fue considerada un abrigo rocoso, en realidad se trata de la boca de una cueva de origen cárstico, hoy colmatada.

La cavidad fue reconocida, antes de la Guerra Civil, por José Miguel de Barandiarán, que encontró materiales musterienses en superficie. Años más tarde, excavó en la boca de la cueva desde 1967 a 1974, documentando nueve estratos, seis de ellos con ocupaciones musterienses (del III al VIII).

Los niveles superiores III, IV y parte del V, fueron excavados en una extensión de $25 \mathrm{~m}^{2}$. Los niveles inferiores se documentaron en una trinchera de unos $6 \mathrm{~m}^{2}$. Las excavaciones recientes han abordado el estudio del depósito arqueológico musteriense, con una metodología multidisciplinar, en el marco de un proyecto sobre las úl- 
timas sociedades neandertales en el Cantábrico (González Urquijo et al. 2005). Se ha utilizado un sistema de nomenclatura alfabético, para distinguir la secuencia de los números romanos utilizados por Barandiarán.

El nivel D se sitúa en la parte superior de la secuencia musteriense del yacimiento. Su cronología aproximada, según los responsables de la excavación, es de 44 Ka BP (Ríos Garaizar 2005, González Urquijo et al. 2005), y se sitúa por debajo de otro nivel, el B, a su vez fechado (Ríos Garaizar 2005) en $42010 \pm 1280 \mathrm{BP}$ sin calibrar (hueso, Beta-144262). Esa parte de la secuencia corresponde al final del Musteriense, con evidencias arqueológicas de las últimas sociedades neandertales europeas. El nivel D se caracteriza por un utillaje lítico de raederas espesas, tipo Quina. Estos útiles llegan al yacimiento como grandes lascas o raederas de sílex importado, y sufren un intenso reavivado in situ. Algunas de las lascas de reavivado de mayor tamaño se reaprovechan como una nueva generación de utillaje retocado. Ese utillaje especializado se complementa con una producción sobre materias primas locales, sobre todo cuarzos y lutitas (Ríos Garaizar 2005; González Urquijo et al. 2005).

Los útiles estudiados son 150 retocadores o fragmentos de retocador, en esquirlas óseas de herbívoro. Dichos retocadores corresponden a las primeras campañas de excavación en el yacimiento (1999-2003). Este utillaje (Lám. I) fue utilizado en las tareas de fabricación y reavivado de las herramientas líticas. En el nivel D también se encontraron dos útiles que hemos denominado "alisadores", a modo de hipótesis funcional, cuyo
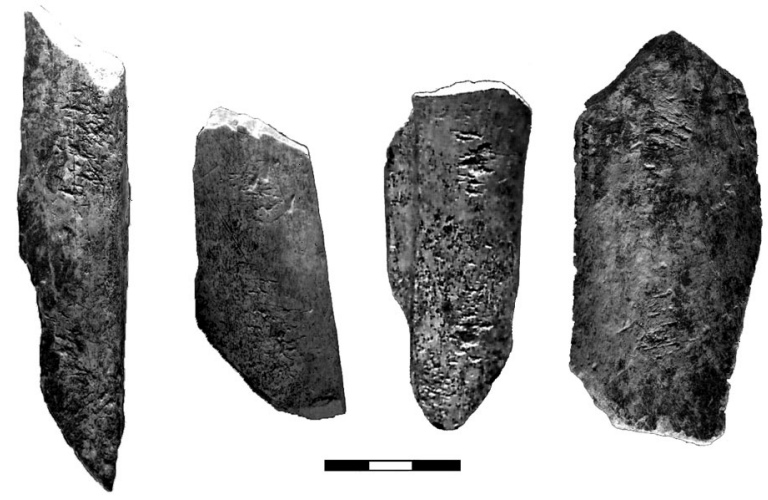

Lám. I. Retocadores en fragmentos diafisarios de huesos largos de grandes ungulados, del nivel D de Axlor. análisis no se incluye en este trabajo. Se trata de un fragmento alargado de diáfisis de gran bóvido, y un fragmento de costilla de la misma especie. Ambos presentan un extremo fuertemente alterado por abrasión, con estrías orientadas y pulido concentrado en dicha zona activa.

El estudio de los materiales se ha realizado desde una perspectiva tecnológica, a partir de la cadena operativa. El objetivo es comprender el proceso de obtención, preparación, uso, reavivado, reciclado y abandono de los útiles en el yacimiento. Se ha tenido en cuenta el sesgo tafonómico y la interrelación de los diferentes aspectos del registro (fauna, industria lítica y otras evidencias), a la hora de estudiar este utillaje.

\section{MÉTODOS Y MATERIALES}

\subsection{Materiales y método arqueológico}

La muestra arqueológica se compone de 150 retocadores de hueso del nivel D (Musteriense final) de Axlor. En su práctica totalidad, se trata de esquirlas diafisiarias de huesos largos de las extremidades de herbívoros. Las excepciones son dos fragmentos de costilla de herbívoro. 130 de los retocadores estaban completos, sin indicios de una fragmentación de uso o postdeposicional, y los otros 20 eran fragmentos de retocador.

El estudio de los materiales arqueológicos se estructura a partir de dos elementos de análisis: el estudio tafonómico de los restos, y la reconstrucción de la cadena operativa. Con esa base, se realizó un estudio de alteraciones tafonómicas, seguido de un análisis morfométrico y traceológico de los soportes, de las zonas de uso y de los estigmas de uso. El análisis incluyó la cuantificación, el procesado estadístico de los datos, y la interacción de los resultados con los datos obtenidos de otros análisis (sobre todo, los paleontológicos y los estudios de la industria lítica). Las determinaciones anatómicas y taxonómicas de los retocadores fueron realizadas por P. Castaños (Fig. 2).

Para estudiar la tafonomía del utillaje óseo del nivel D se analizaron tanto los soportes tecnológicos como el conjunto de la fauna. Para ello, se hicieron una serie de muestreos aleatorios entre los restos de fauna, que se analizaron por separado y también de forma conjunta.

Para estudiar la fragmentación de los restos óseos, el punto de partida ha sido una versión mo- 


\section{RETOCADORES DEL NIVEL D ORIGEN TAXONÓMICO DE LOS SOPORTES}

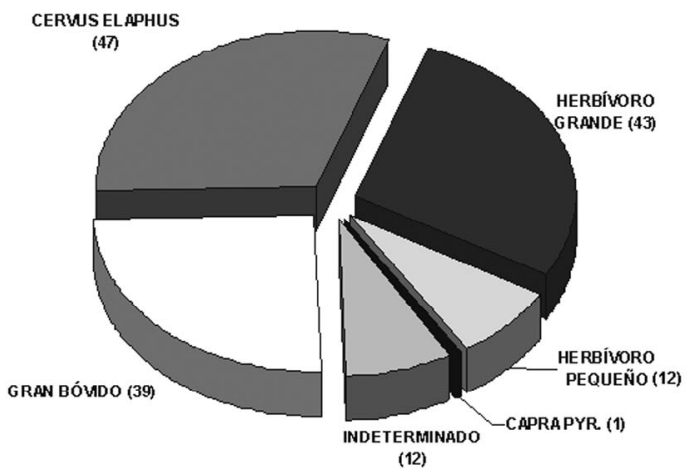

ORIGEN ANATÓMICO DE LOS SOPORTES DE BOSIEISON

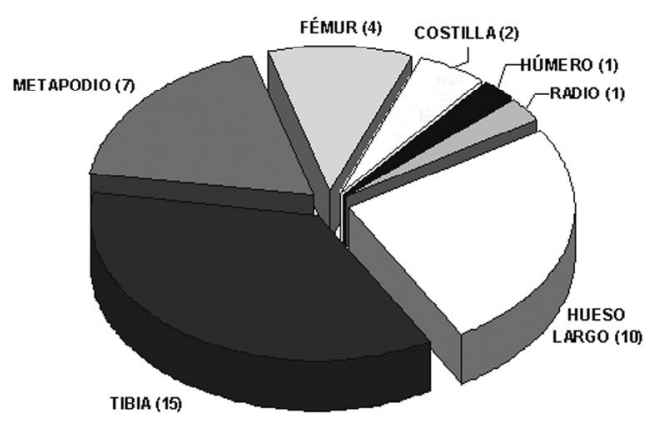

ORIGEN ANATÓMICO DE LOS SOPORTES DE CERVUS ELAPHUS

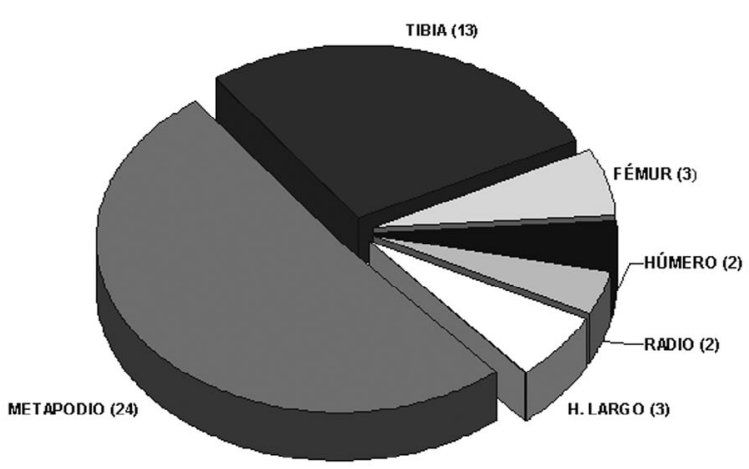

FAUNA DEL NIVEL D HUESOS LARGOS DE LAS EXTREMIDADES

Restos determinados de G. bóvido

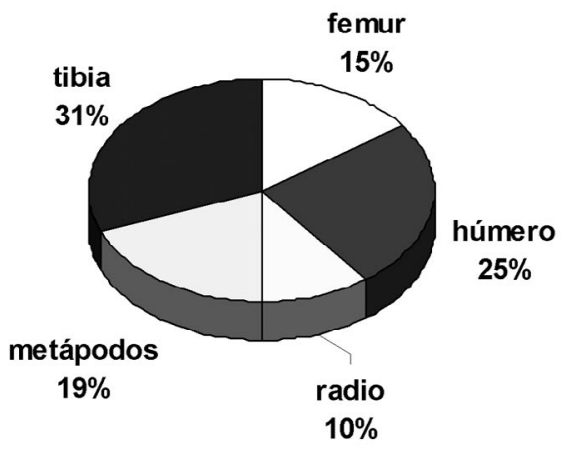

Restos determinados de Cervus el.

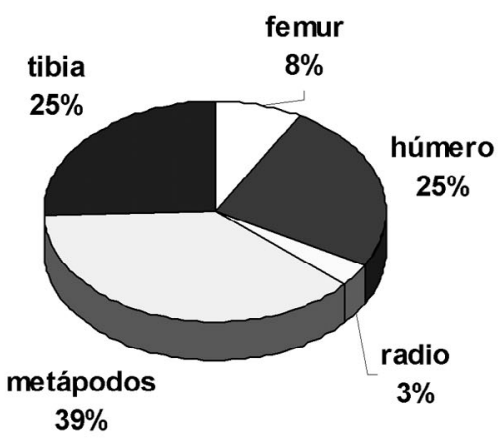

Fig. 2. Determinaciones anatómicas y taxonómicas de los retocadores en hueso del nivel D de Axlor, y porcentajes de representación de los huesos largos de las extremidades de Cervus e. y Bos/Bison, entre los restos de fauna. 
dificada del FFI Score (Fracture Freshness Index) de Outram (2001). El FFI de Outram no recoge la diacronía de las distintas modificaciones (fracturas) sufridas por un determinado hueso. En las muestras examinadas en este estudio, se hallaron con cierta frecuencia distintos tipos de fracturas (en fresco y en seco) sobre un mismo fragmento óseo.

Por ello, se ha preferido un criterio más elemental y objetivo (fresco frente a seco) a la hora de caracterizar los aspectos de una fractura (delineación, paño de fractura y ángulo), en lugar de una gradación relativa de fresco a seco, como señala Outram $(2002,2001)$, que depende en gran medida del criterio subjetivo del observador.

Se recurrió a un Índice Diacrónico de Fractura en Fresco/Seco (IDF F/S) a partir de tres aspectos diferentes de la fractura: la delineación, el aspecto del paño o bisel de fractura, y el ángulo de dicho paño con respecto a la superficie cortical del hueso. A diferencia de la propuesta de Outram, el IDF F/S sólo distingue, en cada uno de los tres criterios, entre huesos frescos y los que no están frescos. Con esta simplificación se pierde un grado de matiz y se gana en objetividad.

El principio operativo es que los huesos que no están frescos han perdido parte de la humedad y del colágeno, y responden de manera diferente a la fragmentación. El IDF F/S permite valorar la nueva fragmentación (posdeposicional) de los restos ya fragmentados.

En la práctica, para determinar el IDF F/S, cada esquirla o resto óseo mayor de $30 \mathrm{~mm}$ de lado mayor es estudiado para determinar el estado de fragmentación y la diacronía de esas fracturas. En cada uno de los aspectos mencionados, se otorga un valor de " 0 ", "1" o " 2 " al resto óseo, en función del estado del hueso. En general, "0" significa que, en ese aspecto, muestra rasgos propios del hueso fresco; "1" significa que muestra rasgos de ambos tipos en el mismo soporte; y "2" que el aspecto analizado muestra rasgos propios del hueso seco. El resultado es un Índice Diacrónico de Fractura (Fresco/Seco) con un valor numérico entre 0 y 6 , resultado de sumar los valores de cada uno de los tres aspectos.

\subsection{Materiales y método experimental}

Como parte de la metodología de estudio, se diseñó un programa experimental. El objetivo era analizar las variables que actúan sobre dos fases de la cadena operativa de los retocadores: la obtención de soportes y el uso de los mismos. El programa tomó como referencia directa los materiales arqueológicos de Axlor.

\section{$1^{\mathrm{a}}$ Fase Experimental: obtención de soportes}

La muestra experimental, para la fase de obtención de soportes, fue de 11 huesos largos de extremidades de bovino (Bos taurus) y cuatro huesos largos de extremidades de ciervo (Cervus elaphus). De estos huesos, nueve estaban frescos (entre ellos todos los de Cervus elaphus) y el resto estaban secos. Durante la primera parte de la experimentación se fracturaron los huesos, con distintas finalidades: en el caso de los huesos secos, para obtener soportes con una fracturación sistemática de las diáfisis. En los huesos frescos, el objetivo principal fue obtener la médula ósea. Por ello la fragmentación no fue sistemática ni se buscó obtener retocadores con formatos específicos.

Para fracturar las diáfisis, se utilizó un utillaje de piedra masivo o de gran tamaño: yunques de caliza (entre 1.710 y 3.760 g) de sección aplanada, y plantas cuadrangulares o discoides; y percutores a base de grandes cantos de arenisca, lutita, caliza y cuarcita, con filos someros (tipo chopper, chopping tool o hendedor). Se utilizaron de forma conjunta dos series de percutores, unos más pesados (de 2.120 a $3.670 \mathrm{~g}$ ), utilizados para conseguir la fractura inicial de las diáfisis más robustas. Y otros más ligeros (entre 900 y 1.700 g), para la fragmentación posterior de la caña ósea. Además, los huesos frescos requirieron de la limpieza y procesado de tendones y elementos articulares, para lo que se usaron lascas de lutita y de sílex. Todas las materias primas líticas (a excepción del sílex) fueron captadas en el entorno (sensu lato) del yacimiento de Axlor.

En cuanto a los paralelos arqueológicos de estos materiales, entre los restos líticos del nivel D se hallaron algunos elementos de gran tamaño de lutita, y abundantes cantos de caliza de diversos tamaños, tanto en las excavaciones recientes como en las antiguas (Barandiarán 1980; Baldeón 1999). Sin embargo, en general, el macroutillaje o utillaje de gran tamaño se halla infrarrepresentado en el área excavada del nivel $\mathrm{D}$, con respecto a la alta densidad de huesos fragmentados en la misma zona.

Para explicar la infrarrepresentación del macroutillaje, se han planteado varias hipótesis, sin que ninguna haya podido ser verificada en el mo- 
mento presente de las investigaciones. Estas hipótesis no son excluyentes entre sí:

a) Utilización en tareas de percusión de cantos, choppers o hendedores de lutita de gran tamaño, que después son aprovechados como núcleos, y reducidos en una secuencia de talla que está presente en el yacimiento, en forma de lascas corticales de primera y segunda generación, productos retocados, y núcleos (en general con tipometrías grandes, que las acercan a las dimensiones probables de un chopper o hendedor reciclado en núcleo).

b) Un recurso a bloques de caliza en bruto, a modo tanto de yunques como de percutores, de forma que la ausencia de modificaciones los hace pasar inadvertidos en el proceso de análisis de los materiales, y los que se recogen son registrados como material geológico.

Por otro lado, existe una evidencia indirecta de la presencia de ese macroutillaje: en los retocadores de hueso, y los restos de fauna revisados del nivel $\mathrm{D}$, se hallaron estigmas de percusión (carga dinámica), como se relata en el apartado de la tafonomía de los soportes, más abajo.

\section{$2^{\mathrm{a}}$ Fase Experimental: uso de los soportes}

Al final de la primera fase experimental, se seleccionaron, como soportes, todas las esquirlas diafisiarias con unas condiciones mínimas para el retoque de útiles líticos. Se aplicó un criterio generalista, sin una selección formal de pesos, morfologías o tamaños.

En una segunda fase experimental, se utilizaron los soportes obtenidos en la primera etapa, en una serie de experimentos de retoque. Se retocaron 49 piezas líticas (47 de sílex y dos de lutita de grano fino). Los soportes no fueron preparados para las tareas de retoque, ni se modificó la morfología original de las esquirlas. Tampoco se realizaron acondicionamientos, salvo la abrasión ligera de cantos cortantes, en huesos frescos. En un único caso, se procedió al raspado previo de la grasa y tendones adheridos al soporte.

\section{RESULTADOS}

\subsection{Tafonomía de los soportes}

- Huellas de carnívoro: en los retocadores del nivel D, las huellas de carnívoros (Blumenschine et al. 1996; Fisher 1995; Lyman 1994; Domínguez-Rodrigo 1994) apenas tienen incidencia. Sólo se detectaron tres casos de soportes con po- sibles roídos de carnívoros de pequeño tamaño. En los muestreos de fauna estudiados los resultados fueron similares, aunque a la baja: se redujo la presencia visible de estas huellas, con incidencias por debajo del $1 \%$.

- Alteración térmica: las evidencias de hueso quemado, carbonizado o alterado por el calor son muy escasas para el nivel D: no hay ningún retocador quemado y la incidencia en los restos de fauna con esas alteraciones es inferior al $1 \%$.

- Fragmentación del hueso: el estudio de los muestreos de fauna del nivel D señala un predominio de las fracturas en fresco (Outram 2001; Alcántara et al. 2006), que se acompaña de una fragmentación postdeposicional de menor incidencia, según muestra el IDF F/S (Fig. 3). La fragmentación secundaria -en seco- no implica un sesgo importante con respecto al utillaje en hueso: más del $90 \%$ de los casos de retocadores sólo presentan fracturas en fresco (incluyendo los fragmentos de útil). El análisis de la distribución de los restos por tamaños (Fig. 3) muestra cómo los fragmentos de diáfisis dominan las categorías de mayor tamaño. Otros tipos de hueso (sobre todo, fragmentos de hueso esponjoso) abundan entre los restos más pequeños.

- Alteraciones de las corticales: se dan alteraciones de la cortical en un $45 \%$ de los soportes. Los datos para los muestreos de fauna son similares en las categorías superiores a $40 \mathrm{~mm}$ de longitud (siendo algo menores entre los restos de menor tamaño). Las alteraciones superficiales se relacionan con la acción hídrica y el ataque químico al componente mineral del hueso y, en menor medida, con fenómenos de arrastre en seco o trampling (Olsen y Shipman 1988). La alteración de las corticales supone un sesgo significativo a la hora de determinar el tipo concreto de tareas realizadas con los retocadores.

- Elementos adheridos al hueso: las adherencias de óxidos de manganeso y concreciones estalagmíticas afectan a un $25 \%$ de la muestra.

- Huellas antrópicas no asociadas al uso de los retocadores: en los retocadores del nivel D se detectaron una serie de huellas tecnológicas, relacionadas con las tareas de carnicería. En torno al $17 \%$ de los retocadores presentan huellas inequívocas de percusión (carga dinámica) producida por un utillaje masivo (Capaldo y Blumenschine 1994). Esos estigmas incluyen puntos de impacto, conos y bulbos de percusión y hackle-marks. También se detectaron estrías cortas y profundas, agru- 

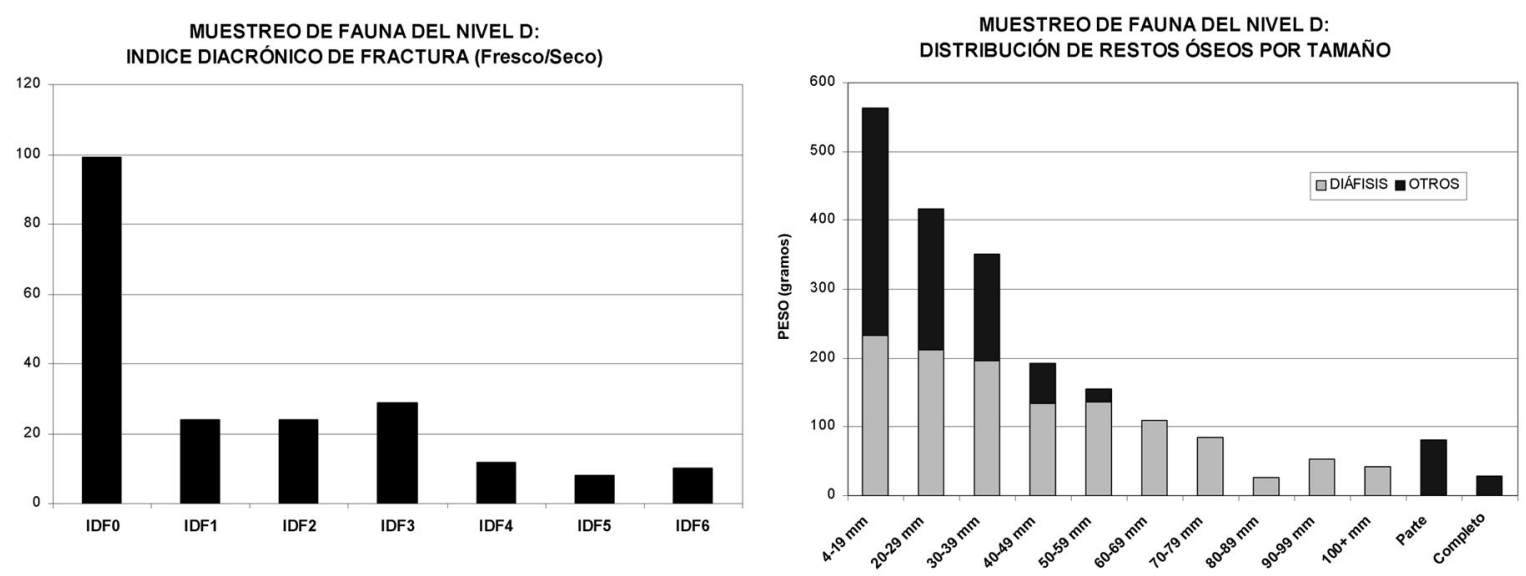

Fig. 3. Índice Diacrónico de Fractura (modificado a partir del Fracture Freshness Index de Outram 2001) de la fauna del nivel D de Axlor, y distribución de la masa de los restos, ordenada según el tamaño de las esquirlas.

padas y orientadas, que aparecen asociadas a otros estigmas de percusión y se producen por el golpeo de un filo tipo chopper sobre la cortical del hueso.

El $38 \%$ de los retocadores tienen marcas incisas de corte, producidas por un filo lítico (CruzUribe y Klein 1994; Greenfield 2006). Los raspados están presentes en 47 retocadores del nivel D, aunque en la mayor parte de los casos están relacionados con las zonas de uso (Lám. II, F). La posición de las huellas y la dirección de los trabajos indican que en 16 casos los raspados no tienen relación con el uso como retocador, y por ello se asocian a tareas de preparación carnicera.

\subsection{Origen de los soportes}

Los soportes de los retocadores fueron determinados (taxón y parte anatómica) por P. Castaños. Provienen, en casi todos los casos, de huesos largos de las extremidades de herbívoros. La excepción son dos costillas de bovino. En líneas generales, dominan el Cervus elaphus, y el Bos/Bison (Fig. 3) con 47 y 39 soportes en cada caso. Hay un único soporte en húmero de Capra pyrenaica, y el resto se reparte entre herbívoro grande (43), herbívoro pequeño o mediano (12) y macromamífero indeterminado (12).

Entre los soportes de Cervus elaphus, destaca la abundancia de metapodios (24 soportes), seguido de la tibia (13). El resto de soportes corresponden a diferentes huesos largos de las extremidades.

En los retocadores sobre hueso de Bos/Bison, la parte anatómica más utilizada es la tibia, con 15 ejemplares. Hay 10 esquirlas que pertenecen a huesos largos y espesos de la extremidad (probablemente tibia o fémur), siete metapodios, cuatro fémures, dos costillas, un húmero y un radio.

Se constata por tanto, la selección de esquirlas que provienen de huesos particularmente densos y pesados de grandes ungulados. En particular, hay una fuerte selección del metapodio de ciervo $y$, en menor medida, la tibia de bovino. En el ciervo, después de los metápodos, la tibia es la siguiente en abundancia.

La comparación de estos datos con los obtenidos a partir de las determinaciones taxonómicas y anatómica del conjunto de fauna -ver Castaños (2005) para una valoración extendida- resalta los elementos de selección. Para el nivel D hay algo más de un $25 \%$ de Capra pyrenaica, mientras que entre los soportes sólo hay un retocador de ese origen. Los soportes provienen principalmente de Bos/Bison y Cervus elaphus, que suman el $67 \%$ de los restos determinados de fauna. Un $5 \%$ de los restos determinados en el nivel D, son de Equus ferus, pero no hay ningún resto determinado de esta especie entre los soportes de los retocadores.

En las determinaciones anatómicas del conjunto de la fauna del nivel D abundan las partes correspondientes a la extremidad, aunque hay una presencia considerable del esqueleto craneal (sobre todo dientes) y, en menor medida, de la carcasa (Castaños, com. personal). Entre los soportes de los retocadores, la importancia numérica de determinados huesos (tibias de Bos/Bison, metapodios y tibias de Cervus elaphus) es superior a su presencia en el conjunto faunístico (Fig. 3). A la inversa, determinados huesos largos bien re- 


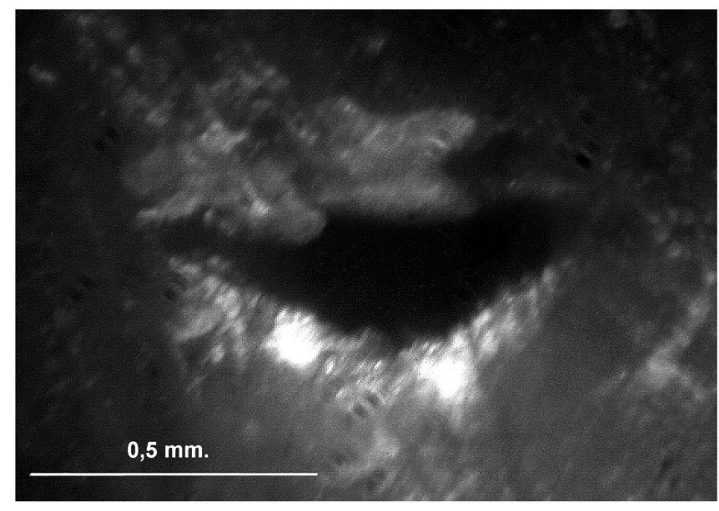

A

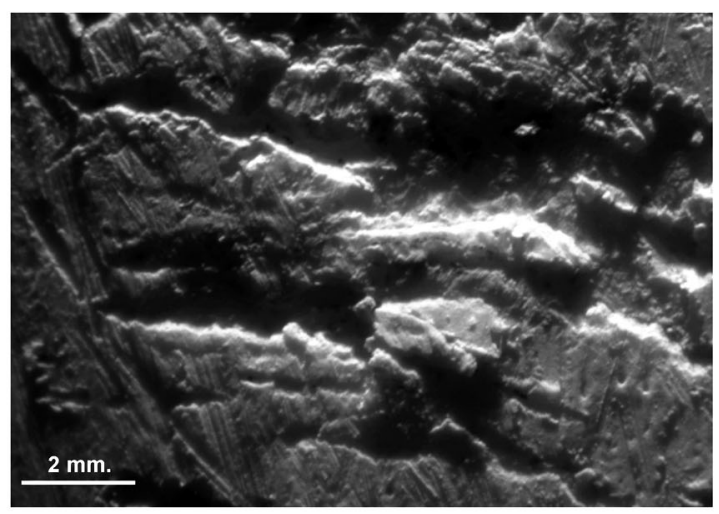

C

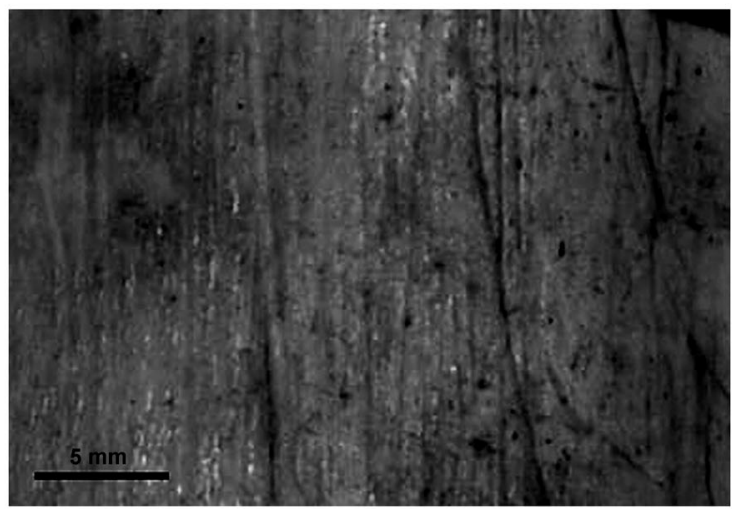

E

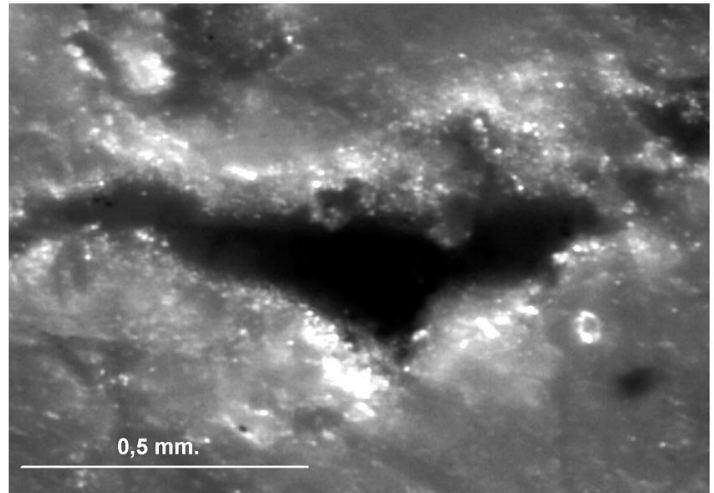

B

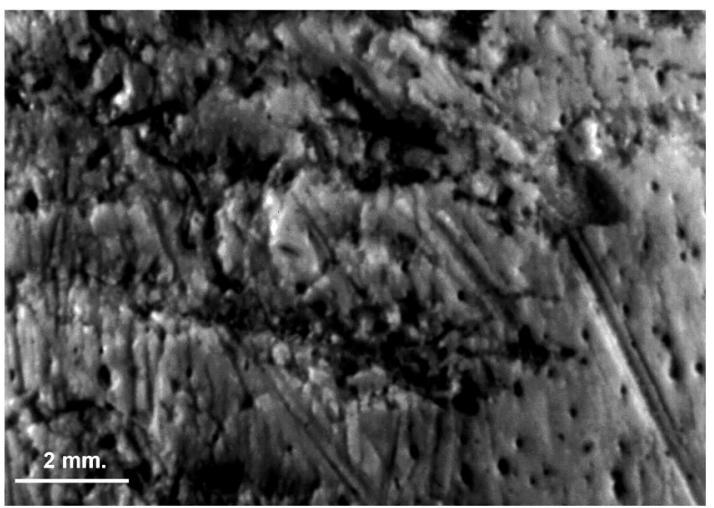

D

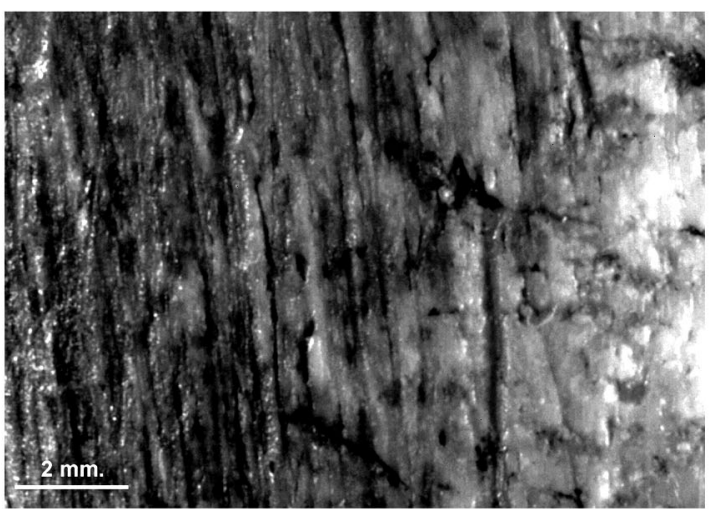

$\mathbf{F}$

Lám. II. A. Impresión triedro experimental. B. Impresión triedro arqueológica (nivel D). C. Impresiones lineales y estrías asociadas, experimentales. D. Impresiones lineales y estrías asociadas, arqueológicas (nivel D). E. Raspado asociado al uso, experimental. F. Raspado asociado al uso, arqueológico (nivel D).

T. P., 66, N. ${ }^{\circ}$ 1, enero-junio 2009, pp. 27-46, ISSN: 0082-5638 doi: 10.3989/tp.2009.09011 
presentados entre la fauna de bovino y de ciervo (húmeros, radios) apenas son utilizados como retocadores (Fig. 3).

\subsection{Morfometría de los soportes}

Para analizar la morfometría de los soportes en su contexto técnico y arqueológico se han cruzado los datos de los retocadores, del programa experimental y de las esquirlas mayores de $40 \times 15 \mathrm{~mm}$ provenientes de los muestreos de fauna del nivel $\mathrm{D}$.

Desde el punto de vista de la morfometría, los soportes miden, en sus valores medios, unos nueve $\mathrm{cm}$ de longitud, tres de ancho (cuatro si medimos la anchura sobre la cara cortical, siguiendo la curvatura del hueso), y en torno a un $\mathrm{cm}$ de espesor máximo. El peso medio es de unos $28 \mathrm{~g}$.

Los soportes obtenidos en el programa experimental, responden en sus valores tipométricos y morfológicos, a una selección coyuntural o "noselección": se recogieron todos los soportes que parecían utilizables, sin criterios definidos de selección. Se dio uso a todos aquellos soportes ob- tenidos que permitían la realización de retoque sin grandes dificultades.

Con esa muestra como elemento de comparación, se han considerado los retocadores del nivel D de Axlor. Se plantea la hipótesis de una obtención coyuntural de los mismos, recogidos de forma directa entre los restos abandonados de la fauna procesada. Es decir, sin apenas selección ni modificación de los soportes, y sin que exista un procesado específico de la materia prima para ese fin.

Si se hubiera producido en el nivel $\mathrm{D}$ ese modo improvisado de obtención de soportes, al comparar las morfometrías de los retocadores arqueológicos y los experimentales, cabría esperar un grado similar de heterogeneidad. Por el contrario, la morfometría de los soportes experimentales se muestra más heterogénea, con respecto a los retocadores arqueológicos, que son más regulares (de tamaños y morfologías menos dispares). Prueba de ello es que los soportes experimentales muestran desviaciones estándar más fuertes (mayor heterogeneidad) en todos los valores morfométricos considerados: la anchura, la longitud, la anchura máxima cortical, el espesor, el peso y el índice de curvatura (Tab. 1).

\begin{tabular}{|c|c|c|c|c|c|}
\hline \multicolumn{6}{|c|}{ A - MORFOMETRÍA DE LOS SOPORTES EXPERIMENTALES (HUESO FRESCO) } \\
\hline $\begin{array}{l}\text { LONGITUD } \\
\quad(\mathrm{mm})\end{array}$ & $\begin{array}{c}\text { ANCHURA } \\
(\mathbf{m m})\end{array}$ & $\begin{array}{c}\text { ANCH. MÁX. } \\
\text { CORTICAL } \\
(\mathbf{m m})\end{array}$ & $\begin{array}{l}\text { ESPESOR } \\
(\mathrm{mm})\end{array}$ & $\begin{array}{l}\text { PESO } \\
\text { (g) }\end{array}$ & $\begin{array}{l}\text { ÍNDICE } \\
\text { CURV. }\end{array}$ \\
\hline PROMEDIO & PROMEDIO & PROMEDIO & PROMEDIO & PROMEDIO & PROMEDIO \\
\hline $\begin{array}{l}93,07 \\
\text { MEDIANA }\end{array}$ & $\begin{array}{c}31,55 \\
M F D I A N A\end{array}$ & $\begin{array}{c}52,04 \\
\text { MEDIANA }\end{array}$ & $\begin{array}{c}11,35 \\
\text { MEDIANA }\end{array}$ & $\begin{array}{c}40,2 \\
M F D I A N A\end{array}$ & $\begin{array}{c}1,98 \\
\text { MFDIANA }\end{array}$ \\
\hline $\begin{array}{l}\text { MEDIANA } \\
\text { 95,54 }\end{array}$ & $\begin{array}{l}\text { MEDIANA } \\
31,08\end{array}$ & $\begin{array}{l}\text { MEDIANA } \\
48\end{array}$ & $\begin{array}{l}\text { MIEDIANA } \\
11,56\end{array}$ & $\begin{array}{l}\text { MIEDIANA } \\
28\end{array}$ & $\begin{array}{l}\text { MIEDIANA } \\
1,64\end{array}$ \\
\hline DESVIACIÓN & DESVIACIÓN & DESVIACIÓN & DESVIACIÓN & DESVIACIÓN & DESVIACIÓN \\
\hline ESTÁNDAR & ESTÁNDAR & ESTÁNDAR & ESTÁNDAR & ESTÁNDAR & ESTÁNDAR \\
\hline 32,02 & 8,51 & $\mathbf{2 0 , 5 8}$ & 4,83 & 38,12 & $\mathbf{0 , 8 8}$ \\
\hline \multicolumn{6}{|c|}{ B - MORFOMETRÍA DE LOS RETOCADORES (COMPLETOS) DEL NIVEL D } \\
\hline $\begin{array}{l}\text { LONGITUD } \\
(\mathrm{mm})\end{array}$ & $\begin{array}{l}\text { ANCHURA } \\
(\mathrm{mm})\end{array}$ & $\begin{array}{l}\text { ANCH. MÁX. } \\
\text { CORTICAL } \\
\text { (mm) }\end{array}$ & $\begin{array}{c}\text { ESPESOR } \\
(\mathrm{mm})\end{array}$ & $\begin{array}{l}\text { PESO } \\
\text { (g) }\end{array}$ & $\begin{array}{l}\text { INDICE } \\
\text { CURV. }\end{array}$ \\
\hline PROMEDIO & PROMEDIO & PROMEDIO & PROMEDIO & PROMEDIO & PROMEDIO \\
\hline 89,37 & 30,33 & 40,52 & 10,40 & 28,73 & 1,34 \\
\hline MEDIANA & MEDIANA & MEDIANA & MEDIANA & MEDIANA & MEDIANA \\
\hline 86,29 & 28,79 & 39 & 9,8 & 24 & 1,30 \\
\hline DESVIACIÓN & DESVIACIÓN & DESVIACIÓN & DESVIACIÓN & DESVIACIÓN & DESVIACIÓN \\
\hline ESTÁNDAR & ESTÁNDAR & ESTÁNDAR & ESTÁNDAR & ESTÁNDAR & ESTÁNDAR \\
\hline 24,22 & 8,12 & 13,47 & 3,90 & 19,02 & 0,32 \\
\hline
\end{tabular}

Tab. 1. Estadísticas morfométricas generales, de los soportes de retocadores (A. experimentales en hueso fresco; B. nivel D de Axlor). 
Por otro lado, la hipótesis de que no ha existido una selección implica que los retocadores deben distribuirse, en cuanto a sus dimensiones, de forma más o menos aleatoria dentro del conjunto de las esquirlas de fauna del nivel D. La fig. 4 muestra como las esquirlas de fauna y los retocadores pueden pertenecer a una misma distribución, pero los retocadores forman un subgrupo específico. Ese grupo se caracteriza por unas dimensiones situadas en el extremo mayor de la distribución de esquirlas óseas.

La evidencia del análisis comparativo de restos de fauna, retocadores y programa experimental permite descartar la hipótesis de la no-selección por morfometría, para los soportes del nivel D. El resultado indica la existencia de una selección de los soportes, por sus variables morfométricas. Esas variables reflejan, desde un punto de vista tecnológico, cualidades morfotécnicas como la prensibilidad, la masa, la densidad y la morfología de la zona activa.

Balance de los aspectos taxonómicos, anatómicos y morfométricos

La selección de los soportes, responde por tanto a criterios morfotécnicos (por las cualidades técnicas y la morfología del retocador), y está organizada a partir de determinados taxones y partes anatómicas, que no son azarosos. Esto implica una intencionalidad y sugiere la posibilidad de una previsión desde, al menos, el proceso de fracturación de los huesos largos de los grandes ungulados.

Si bien no se puede hablar de producción específica y singular de los soportes, la evidencia refuerza una idea: no se trata de una selección ar-

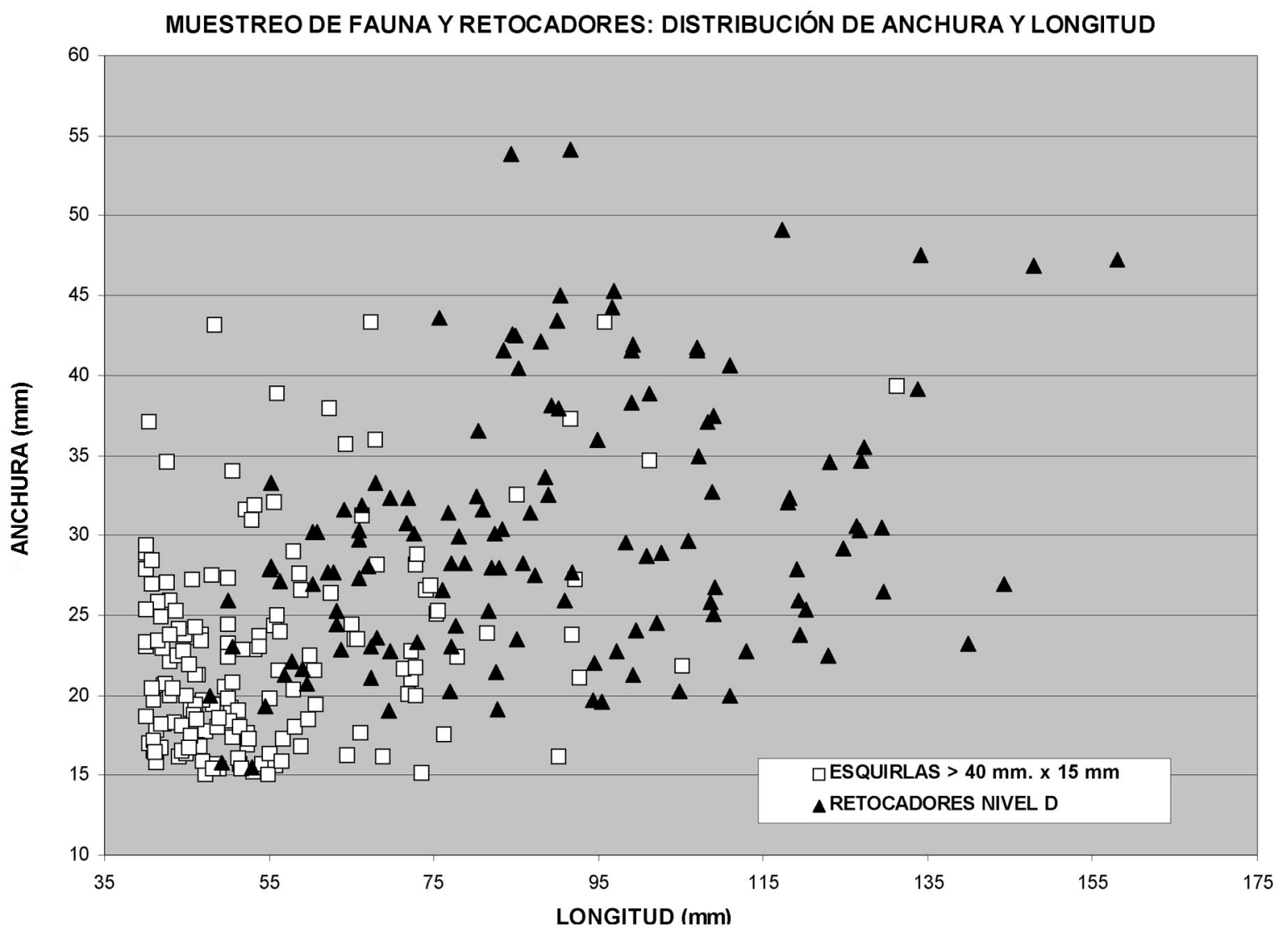

Fig. 4. Distribución de las dimensiones (anchura y longitud) de los retocadores del nivel D, comparados con los muestreos de esquirlas de fauna (mayores de $40 \times 15 \mathrm{~mm}$ ). 
bitraria de esquirlas de fauna entre los restos presentes en el lugar de procesado cárnico. En ese sentido, los datos faunísticos y métricos, junto con las comparaciones establecidas, prueban que los soportes han sido seleccionados con criterios morfotécnicos muy marcados y que en esta selección, hay al menos un elemento de organización basado en el origen taxonómico y anatómico de los soportes.

Ahora bien, en este punto se plantea una cuestión, sobre el momento en que se formulan los primeros criterios de selección: si la selección es a posteriori, a partir de las esquirlas de fauna producto del procesado cárnico; o bien se realiza en el momento de fracturar las diáfisis de los huesos largos (seleccionando en ese momento los soportes adecuados y condicionando, por tanto, la forma de fracturar los huesos). En este caso, estaríamos hablando de una producción intencional de los soportes, compatible con el aprovechamiento alimenticio de los huesos.

Esta cuestión, en proceso de estudio por nuestra parte, en el marco de una ampliación del programa experimental, aun no tiene una respuesta definitiva. No obstante, los datos de las determinaciones taxonómicas y anatómicas de los soportes, y los restos de fauna, sugieren que los soportes no provienen de partes anatómicas o taxones aleatorios, sino -en su mayor parte- de huesos específicos de determinados taxones (Fig. 3). En ese sentido, resulta poco plausible que una selección a posteriori de los restos de fauna presentes en el yacimiento reagrupe los fragmentos de diáfisis de determinados huesos (tibia, metápodo, fémur) y determinados taxones (bovino, Cervus), en perjuicio de otros taxones y partes anatómicas, presentes -en abundancia- en el yacimiento.

En los retocadores en hueso de Cervus (Fig. 3) abundan los metápodos (en gran número), las tibias y los fémures. Pero los húmeros, abundantes entre los restos de fauna, apenas aparecen como soportes. En el caso de los soportes de Bos/Bison, (Fig. 3) hay una alta proporción de fragmentos de tibia, metápodos y fémures. De nuevo, los húmeros, que abundan entre los restos de fauna, apenas están representados entre los retocadores de hueso de bovino. Lo mismo sucede, en menor proporción, con los fragmentos de radio-ulna.

Estos datos no pueden considerarse probatorios de una producción intencional de los soportes, pero sugieren que la selección de los mismos es un elemento ya presente en la fractura de las diáfisis para obtener la médula. De corroborarse este extremo, probaría la interacción de la obtención de los soportes, con el procesado carnicero de las presas de caza.

\subsection{Uso de los soportes}

\section{Estigmas de uso}

La experimentación permitió la observación de los estigmas o huellas producidas por el trabajo de retocar un filo lítico, corroborando los resultados de otros estudios similares (Armand y Delagnes 1998; Bourguignon 2001). Los estigmas individuales se clasificaron en una serie de categorías, que fueron detectadas y analizadas en la muestra arqueológica. Esas categorías son:

- Impresiones lineales (Lám. I; Lám. II, C y D): huellas alargadas, estrechas y profundas, en forma de huso, ungulación o media luna. Se producen por el impacto de un filo lítico sobre la materia ósea.

- Impresiones triedro (Lám. II, A y B): negativos en forma de triedro o semicono, del impacto de una denticulación, talón apuntado u otro tipo de apuntamiento que sobresale en la pieza lítica. Se producen cuando el retocador golpea puntos destacados del filo.

- Estrías (Lám. II, C y D): líneas incisas rectas o ligeramente curvadas, directamente asociadas a las huellas impresas, que se producen cuando un golpe de trayectoria amplia y curvilínea impacta sobre el retocador oblicuamente, lo que facilita el arrastre del golpe. Las estrías se marcan allí donde se produce un contacto oblicuo entre el filo lítico y el retocador, sin que llegue a impactar. Las estrías tienden a aparecer agrupadas, paralelas entre sí, y formando "colas de cometa" en la parte superior de la zona de uso. Por lo general quedan lateralizadas, reflejando la trayectoria de la percusión. Es importante distinguir estas marcas, que pueden llegar a formar zonas estriadas relativamente densas, de los raspados de preparación. Los criterios para esta distinción son: a) la asociación estrías-impresiones, b) su posición en el soporte y respecto a la zona de uso, y c) la orientación y dirección de las mismas.

Los retocadores del nivel D tienen una media de unas 24 impresiones lineales por zona de uso, con una orientación en torno a los $80^{\circ}$ respecto al eje longitudinal del soporte. La longitud media de las impresiones es de 2,76 mm. Aparecen estrías 
en 108 de los 150 retocadores, con una media de cinco estigmas (por soporte con estrías). Se detectaron impresiones triedro en 66 casos.

La orientación de las impresiones lineales (en torno a los $80^{\circ}$ ) tiene una escasa desviación media y es casi perpendicular al eje longitudinal del soporte. Eso significa que las huellas tienen una orientación que es subparalela al eje transversal.

La orientación depende de las posiciones relativas del retocador y la pieza lítica, en el momento del impacto y dichas posiciones dependen del modo de prensión de ambos útiles, y de la trayectoria de percusión. La orientación predominante en los retocadores del nivel D señala unos gestos controlados, con una trayectoria poco oblicua.

El programa experimental muestra que es posible inferir algunos tipos concretos de tareas (tipo de retoque) a partir de los estigmas de uso, siempre que se dé una buena conservación de las corticales del hueso. En particular, se constató la posibilidad de diferenciar tareas de retoque simple, sobre lascas poco espesas, de la dinámica propia del retoque Quina (Bourguignon 2001). Los criterios de diferenciación evidenciados por el programa experimental son: a) la longitud media de las impresiones, que es mayor en el caso del retoque Quina; b) la presencia relativa de "cúpulas" (desconchados masivos de utilización) en las zonas de uso, mayor en el retoque Quina; y c) la presencia de estrías asociadas al uso, mayor en el retoque simple.

En el nivel D existe un grado considerable de alteración en las corticales de los retocadores. Con un sesgo (alteración cortical) que afecta a casi la mitad de la muestra, y modifica varios parámetros esenciales (tamaño medio de las impresiones, abundancia relativa de estrías, número de impresiones individuales) no es posible inferir -de las impresiones- el tipo concreto de retoque realizado en el nivel D.

\section{Zonas de uso}

Las zonas de uso de los retocadores se forman por la acumulación de estigmas (sobre todo huellas lineales) en la zona activa del soporte. De los 150 retocadores del nivel D, 106 tenían una sola zona, 6 mostraban tres zonas de uso, 32 tenían dos zonas de uso y 6 presentaban huellas de uso dispersas, sin una zona definida.

Las zonas de uso se sitúan muy próximas a uno de los extremos del soporte, que considera- mos como proximal (orientando tecnológicamente el útil). Esto es consecuencia del uso a modo de martillo, en percusión, sujetando el retocador por un extremo, y golpeando la pieza lítica con el otro. En los retocadores dobles, las dos zonas de uso están situadas (por lo general) en ambos extremos del soporte. Cuando aparecen tres zonas de uso, dos están en los extremos y una tercera, de menor importancia, se sitúa próxima a una de las anteriores.

En los retocadores dobles, es habitual una jerarquización de la importancia de las zonas de uso: hay una principal, algo más grande, con numerosas huellas de uso, y con una superficie muy erosionada; y otra secundaria, con menor número de huellas (Lám. I).

Las zonas de uso de los retocadores del nivel $\mathrm{D}$ miden en torno a $20 \mathrm{~mm}$ de largo y $12 \mathrm{~mm}$ de ancho en sus valores medios. Se sitúan, como norma general, centradas en el eje transversal, y ligeramente lateralizadas hacia la derecha.

El programa experimental permitió comprobar que el uso de este tipo de retocadores por un sujeto diestro, en tareas de retoque por percusión, crea un patrón general de lateralización de las zonas de uso hacia la derecha. La lateralización deriva de la forma de sostener el útil y de la trayectoria de percusión.

Este patrón puede no ser evidente en los casos individuales, pero aparece en el tratamiento estadístico del conjunto. Dado que los extremos de los útiles tienen morfologías heterogéneas, y condicionan el modo de prensión de cada instrumento, ese patrón de lateralización sólo se percibe al analizar cuantitativamente las medidas de un número amplio de retocadores.

La lateralización hacia la derecha de las zonas de uso, presente en los soportes del nivel D (Fig. 5), indica un uso predominante por parte de sujetos diestros, al igual que en la experimentación.

El grado de lateralización (mayor o menor), combinado con la orientación de las huellas, también es un instrumento de inferencia. En el programa experimental, los trabajos realizados mostraron un alto grado de lateralización, combinado con una orientación heterogénea y abierta de las impresiones lineales respecto al eje del soporte. Esta combinación de variables se deriva de una gestualidad concreta, que se define por una prensión laxa del soporte, gestos oblicuos y trayectorias curvas, de derecha a izquierda (desde el pun- 


\section{LATERALIZACIÓN DE LA ZONA DE USO POR INTERVALOS}

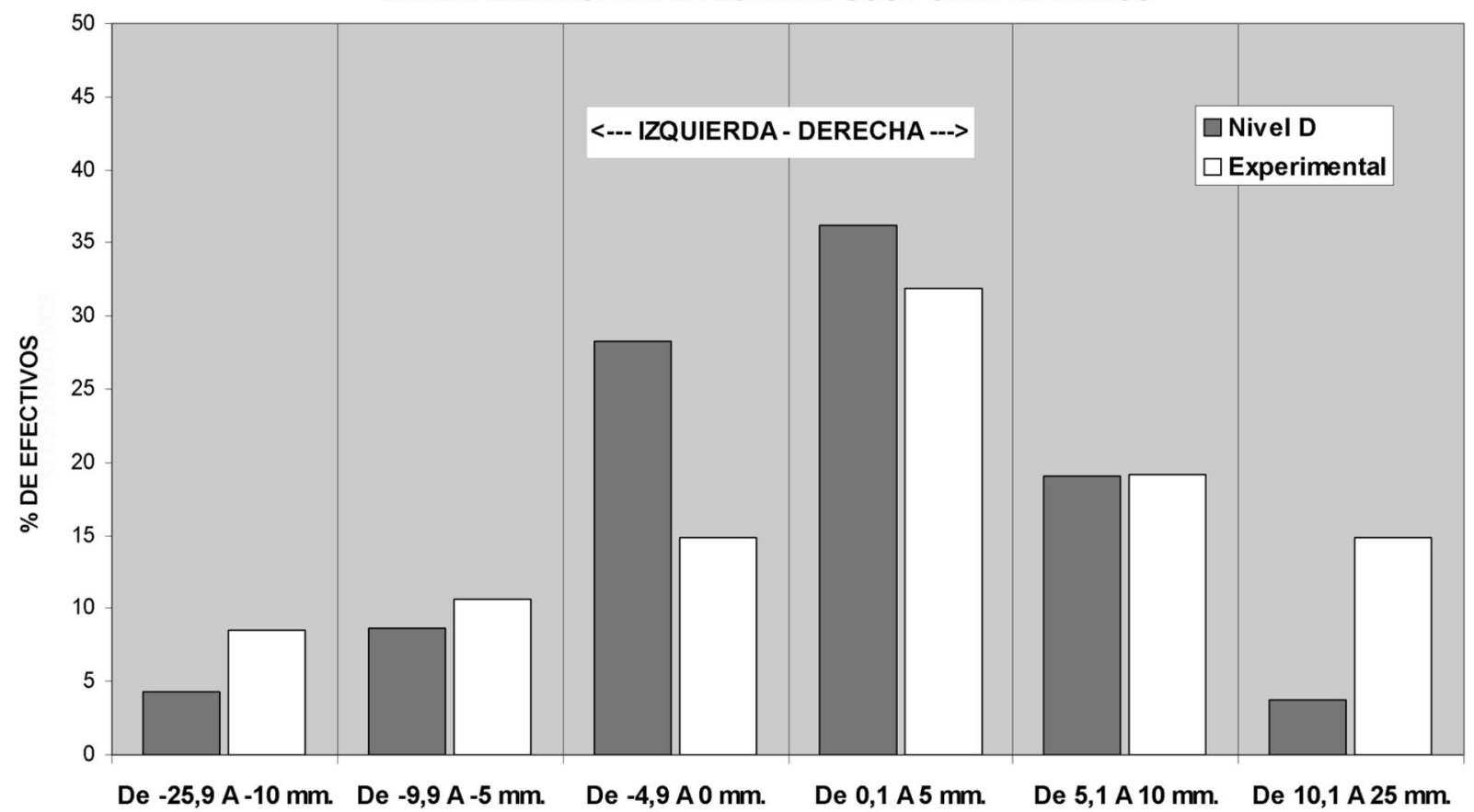

Fig. 5. Lateralización de las zonas de uso por intervalos. La distancia de lateralización se calcula restando la distancia (de la zona de uso) al extremo derecho del útil, de la distancia (de la zona de uso) al extremo izquierdo del útil. De este modo la lateralización de un soporte hacia la izquierda se expresa en unidades negativas, y hacia la derecha, en unidades positivas.

to de vista del sujeto). Frente a esa gestualidad, se comprobó que un gesto más controlado, con trayectorias rectas, produce patrones de huellas menos lateralizados y con una orientación subparalela al eje transversal del soporte.

La escasa lateralización de las zonas de uso, en el conjunto del utillaje del nivel D (Fig. 5), junto con una orientación sub-paralela al eje transversal, apunta a un uso con gestos controlados, bastante rectos, en los que la trayectoria del retocador hacia la pieza lítica no tiene una marcada oblicuidad. Ese tipo de gestos controlados, de trayectorias poco oblicuas respecto a la posición del sujeto, se ha vinculado a las distintas fases del retoque Quina (Bourguignon 2001).

En el programa experimental, se percibió que la acumulación de impresiones provoca una erosión de las zonas de uso. Esta erosión hace menos efectivo el retoque. La dificultad puede soslayarse con el recurso a otra zona activa para retocar o bien, con el reavivado de la misma zona mediante el raspado de la superficie con una lasca lítica. De los 47 casos de retocadores que presentan raspados (Lám. II, D), 12 están asociados de forma inequívoca a las huellas de utilización (se han ha- llado relaciones diacrónicas de superposición entre los estigmas lineales y el raspado). Otros 19 casos de raspado no se asocian de forma tan directa, pero se yuxtaponen a la zona de uso, indicando también una posible asociación con la misma.

Las zonas más erosionadas son aquellas que presentan "cúpulas" de uso (1). En el nivel D, 83 de los 150 retocadores y fragmentos presentan esas características "cúpulas" de uso (es decir, un $55 \%$ de los soportes). Si consideramos el subconjunto de los retocadores con dos o más zonas de uso, las "cúpulas" están presentes en 27 de 38 (en torno al $71 \%$ de los casos). Para comprobar si esta relación entre "cúpulas" y número de zonas de uso es significativa, se ha realizado un test del Chi-cuadrado (Tab. 2). El resultado indica la existencia de una relación significativa entre ambas variables, al umbral de significación de 0,01. Este dato confirma que la presencia de cúpulas está relacionada con la intensidad del trabajo y es

(1) «Cúpulas» es la denominación que hemos escogido para los desconchados masivos que se producen al erosionarse la materia ósea de la zona de uso, por la repetición de los impactos al retocar. 


\begin{tabular}{|lcc|}
\hline \multicolumn{2}{|c|}{ ANÁLISIS DE CHI-CUADRADO DE LAS VARIABLES "PRESENCIA DE CÚPULAS" Y "NÚMERO DE ZONAS } \\
DE USO EN LOS RETOCADORES" \\
\hline \multicolumn{2}{|c|}{ PRESENCIA CÚPULAS } & AUSENCIA CÚPULAS \\
\hline RET. CON 1 ZONA USO & $\mathbf{4 9}$ & $\mathbf{5 7}$ \\
RET. CON 2 O MÁS ZONAS & $\mathbf{1 1}$ & $\mathbf{2 7}$ \\
Prueba del Chi-cuadrado: & 3,436 & \\
Chi-cuadrado (valor observado) & 2,706 & 1 \\
Chi-cuadrado (valor crítico) & 0.64 \\
GDL & 1 & \\
p-value unilateral & & \\
Alpha & & \\
Conclusión: al umbral de significación Alfa=0,010 se puede rechazar la hipótesis nula de independencia entre las filas \\
y columnas. Dicho de otro modo, la dependencia entre las filas y columnas es significativa. \\
\hline
\end{tabular}

Tab. 2. Análisis de Chi-cuadrado que muestra la dependencia de las variables "Presencia de cúpulas" y "Número de zonas de uso" en los retocadores del nivel D de Axlor.

uno de los factores que condicionan el abandono de una zona de uso.

Desde el punto de vista de la interpretación arqueológica, se puede afirmar que la formación de cúpulas en la zona activa del retocador reduce la eficacia del útil, y por ello el sujeto que lo emplea cambia el modo de prensión (gira el retocador $180^{\circ}$ y utiliza el extremo opuesto).

Los retocadores con tres zonas de uso presen$\tan$ (en cinco de los seis casos) huellas de raspado asociadas a las zonas de uso. Los raspados indican un fuerte reavivado de las zonas de uso, para alargar la vida de estos retocadores, reforzando la idea de un uso intenso.

\subsection{Reconstrucción de la cadena operativa}

1. Obtención: los retocadores de hueso del nivel D se obtienen de las diáfisis de huesos largos (de ungulados) que son procesados, con finalidad alimenticia, en el yacimiento. A partir del conjunto de fauna disponible, se opta por utilizar esquirlas de ciertas especies (Bos/Bison, y Cervus elaphus) y de determinadas partes anatómicas (tibias de bovino y metápodos $\mathrm{y}$, en menor medida, tibias de ciervo).

Los soportes se diferencian notablemente del conjunto de esquirlas de fauna, ocupando los extremos mayores de la distribución (son los fragmentos de mayor tamaño). Comparados con la muestra experimental, obtenida sin selección de los formatos, son más homogéneos y regulares.

Los retocadores se seleccionan por el tamaño, la forma y la densidad. Estos criterios se explican en clave tecnológica: apuntan a la obtención de soportes aptos para tareas de retoque, con una masa y densidad suficientes, y un tamaño y forma adecuados a su prensión y manipulación. La búsqueda de formatos convexos y planoconvexos se relaciona con una mayor facilidad de prensión del útil, y con la obtención de una morfología eficaz para el retoque.

Se ha probado que no existe una selección arbitraria de esquirlas de fauna, entre los restos del procesado cárnico de las presas. Además, existen elementos que sugieren que la selección de los soportes se produce en el momento de fragmentar el hueso, para acceder a la médula. En ese caso, se abriría la posibilidad de una producción intencional de los soportes.

Tanto si sólo hay una selección con criterios morfotécnicos, como si hay una producción intencional, la obtención de los soportes evidencia una capacidad de planificación y previsión, en relación a las tareas de gestión del utillaje en piedra.

2. Preparación: no se han hallado evidencias inequívocas de preparaciones anteriores al uso de los soportes. Entre los 130 retocadores completos del nivel D hay algunos casos (6) de soportes con posibles preparaciones por percusión, que tiene como consecuencia pérdidas de fragmentos de materia (lascas) en sus laterales o en el extremo proximal. Pero en ninguno de estos casos las huellas se pueden asociar, de manera definitiva, a un tratamiento específico del soporte, posterior al procesado carnicero.

3. Uso: el estudio de los estigmas de uso apunta a un uso predominante por parte de suje- 
tos diestros, en tareas de percusión que implican el golpear sobre el filo de piezas líticas, con gestos controlados, y no muy oblicuos.

Como se ha explicado, el sesgo tafonómico hace imposible una inferencia directa de los tipos de tareas realizadas con los retocadores del nivel $\mathrm{D}$, a partir del análisis traceológico de las huellas de uso. La imposibilidad de inferir - con un mínimo de certeza- el tipo de tareas, condiciona que el grueso de la información que manejamos al respecto sea de tipo contextual. Las evidencias disponibles (masa y morfología de los percutores, lateralización de las zonas de uso y orientación de las huellas) junto con la información contextual, apuntan a trabajos de retoque y reavivado del utillaje Quina del nivel D.

En este nivel, las tareas de gestión del utillaje se centran en el reavivado de las raederas Quina. Además, algunas de las lascas de retoque obtenidas del filo de esas raederas (las de mayor tamaño) a su vez se retocan, conformando nuevos útiles. Dichos útiles son raederas y lascas retocadas de perfil delgado y filos agudos (frente al perfil carenado y los filos espesos de la raedera Quina). Junto a los 150 retocadores del nivel D, en este nivel se hallaron (en las campañas 1999-2003) 2879 restos líticos, en su mayor parte de sílex (2085). Parte de esos materiales, en concreto 761 restos superiores a $10 \mathrm{~mm}$, de las campañas 1999-2001, han sido analizados desde la cadena operativa (2). En ese conjunto, el sílex supone el $81 \%$ de la muestra, y el resto de materiales son lutitas, cuarzos y cuarcitas. Hay un total de 50 útiles retocados, 61 restos de talla, 1 núcleo y 344 lascas de retoque (no modificadas), que son, en su práctica totalidad, subproductos del reavivado de las raederas. El utillaje retocado del nivel D está compuesto por raederas (29), lascas retocadas (9), denticulados (8), cuchillos con dorso (2), y rabots (1).

Como balance, podemos caracterizar la industria lítica del nivel D como un conjunto en el que dominan los restos de retoque de las piezas de sílex (fundamentalmente, raederas). Los soportes originales llegarían al yacimiento en forma de grandes lascas preformadas o raederas Quina de gran tamaño, que sufren un intenso proceso de reavivado y reacondicionamiento in situ. En

(2) Ríos Garaizar, J. 2007: Industria lítica y sociedad en la Transición del Paleolítico Medio al Superior en torno al Golfo de Bizkaia, Tesis Doctoral, Universidad de Cantabria. ese proceso están directamente implicados los retocadores en hueso. Ese reavivado y reacondicionamiento deja, como productos finales, raederas Quina prácticamente agotadas, cortas, espesas y de pequeño tamaño. A eso se añade un cierto número de lascas de retoque que a su vez son convertidas en productos retocados. En ese proceso de reavivado y reacondicionamiento, los retocadores de hueso pueden, según se comprobó experimentalmente, estar presentes en casi todas las fases de reavivado de las raederas Quina. La excepción ocasional serían las lascas tipo IV (Bourguignon 2001) que a menudo requieren del uso de un percutor duro o semiduro. Ese tipo de percutores más robustos están también presentes en el nivel D, en forma de cantos de arenisca (algunos con estigmas de percusión).

En el programa experimental se llevaron a cabo todas las fases del retoque Quina -ver Bourguignon (2001) para una descripción completa del proceso- con retocadores de hueso fresco o semifresco. Como se ha dicho, se observó la existencia de una dificultad con la obtención de lascas tipo IV, al percutir con retocadores de hueso, en comparación con los percutores "semiduros" de piedra arenisca.

A pesar de esa excepción, el hueso fresco y semifresco ofrece una elasticidad suficiente para transmitir la fuerza en extracciones sobrepasadas poco espesas, y en la mayor parte de los lascados anchos y cortos del retoque Quina.

Los retocadores óseos espesos, con una masa de al menos $20 \mathrm{~g}$, y con morfologías planoconvexas, son adecuados para casi todas las tareas, con la excepción de la obtención de las lascas más anchas y espesas. Estas se ejecutan mejor con retocadores de hueso muy espesos, con morfologías convexas, como por ejemplo los metápodos de ciervo de mayor masa (animales machos adultos).

La vinculación de los soportes del nivel D con los trabajos Quina no tiene porqué ser exclusiva. El conjunto de huellas presentes en los retocadores puede responder a una variedad de tareas, en las que el retoque Quina tenga preeminencia.

4. Mantenimiento: la presencia de dos o más zonas de utilización en 38 retocadores del nivel D señala al uso consecutivo de ambos extremos del útil, como estrategia de mantenimiento. La experimentación muestra que la acumulación de estigmas provoca la erosión de las zonas de uso, y las hace menos efectivas. Esa dificultad puede soslayarse utilizando otra zona para retocar, o con el 
reavivado de la misma por raspado. Por otro lado, una parte de los soportes (12) muestra raspados directamente asociados a las zonas de uso, y otro grupo de soportes (19) tiene raspados que pueden estar asociados al uso. El raspado con una lasca lítica es una estrategia que permite reavivar la zona activa, sin necesidad de cambiar el modo de prensión.

5. Reciclado y abandono: no se dan procesos de reciclado de los retocadores en otro tipo de útiles en el nivel D de Axlor. En cuanto al abandono, un elemento que puede finalizar el uso del retocador es su rotura. Los soportes que aparecen con una posible fractura de uso (20 efectivos de 150) en el nivel $D$, muestran -en 18 casos- idénticos patrones de fragmentación en fresco. De esos 18 casos, hay 6 en los que la delineación de la fractura afecta directamente a la zona de uso.

Por lo tanto, hay un componente de fractura de los soportes, que afecta al momento de abandono de los mismos. Sin embargo, esto sólo aporta una parte -pequeña- de la explicación. En líneas generales, los soportes fueron abandonados intactos después de uno o varios usos, relativamente intensos, que producen la formación de una o (a veces) varias zonas de uso.

\section{DISCUSIÓN}

\subsection{El concepto de "industria ósea poco elaborada"}

El término de "industria ósea poco elaborada" se viene utilizando para denominar al utillaje en hueso del Paleolítico antiguo (medio e inferior). Uno de los principales problemas de este término es que la denominación tiene su origen en una comparación directa con las industrias de elaboración de hueso y asta en el Paleolítico superior. Existe un prejuicio de facto en la disciplina, establecido sobre la base de que las industrias "poco elaboradas" son de hecho "útiles de fortuna". Desde ese punto de vista, dichos útiles serían obtenidos de forma inmediata o casual, sin que en su obtención, o en las tareas para las que se utilizan, medien decisiones o procesos de pensamiento de una mínima complejidad (Chase 1990).

Para algunos autores, las técnicas de conformación del hueso y el asta, que aparecen en Europa a partir del Paleolítico superior, son parte de un kit técnico e intelectual más avanzado, en un sentido progresivo.

En esa línea interpretativa, la industria ósea del Paleolítico superior constituye una prueba de la superioridad cognitiva del Homo sapiens frente a los neandertales (Noble y Davidson 1996). Del mismo modo, las industrias óseas "poco elaboradas" son prueba de la inferioridad de los grupos del Paleolítico medio. Es indudable que el registro arqueológico muestra la presencia de una industria ósea elaborada, con una creciente riqueza simbólica, a partir de los inicios del Paleolítico superior. Pero este hecho no significa que las industrias llamadas "poco elaboradas" puedan igualarse con una menor capacidad cognitiva o intelectual.

Por otro lado, existe una dificultad en la nomenclatura, con el propio concepto de "industria", que a menudo se iguala, exclusivamente, al utillaje del Paleolítico superior: desde una visión normativa, la definición del término "industria ósea" se ha hecho depender del grado de estandarización de las labores. De ese modo, lo que no responde a los rasgos propios de las industrias clásicas del Paleolítico superior, no se considera industria ósea (Patou-Mathis 1999).

Este tipo de enfoques establece unos a priori (lo que es industria ósea y lo que no), que tienden a destacar la importancia de las industrias de tipo Paleolítico superior, e indirectamente relega a un papel secundario a las industrias "poco elaboradas". En general, dicho enfoque aleja el foco de atención de ciertas cuestiones sustanciales, como la obtención y selección de los soportes, o el uso y la función del utillaje.

Lo que resulta innegable, es que la industria ósea musteriense, bajo la etiqueta de "poco elaborada", no ha recibido la debida atención. El presente trabajo tiene la vocación de mostrar el potencial informativo de dicho utillaje.

Cabe cuestionarse la necesidad de mantener la noción de "poco elaborada" para la industria del Paleolítico inferior y medio, que tiene connotaciones cualitativas, y conlleva la comparación con una realidad diferente (las industrias de conformación del hueso y el asta, en el Paleolítico superior).

Por todo ello, sugerimos que la idea de "industria poco elaborada", como término que describe un conjunto tecnológico, puede ser abandonada (ya que siempre tendrá una connotación comparativa). 
El estudio del utillaje óseo, en el Paleolítico europeo, muestra un extenso panorama investigador centrado en las industrias óseas del Paleolítico superior. Esta realidad se corresponde con un verdadero vacío investigador en lo referente al Paleolítico inferior y medio -con escasas y notables salvedades (Valensi 1996; Gaudzinski 1999; Anzidei 2000; Patou-Mathis 2002).

Así, en el ámbito regional del yacimiento de Axlor, encontramos un alto número de yacimientos en los que se mencionan conjuntos de utillaje en hueso, sobre todo retocadores, que no han sido estudiados en profundidad. Parte de estos conjuntos se encuentran en proceso de estudio o revisión por nuestra parte (Axlor, Amalda, Cueva Morín, Peña Miel). Otros conjuntos, que también han librado utillaje en hueso, como Covalejos, Valdegoba y Prado Vargas, deberían convertirse en objeto de atención de las investigaciones sobre utillaje óseo en el Paleolítico medio.

La cadena operativa, como elemento que imbrica toda una variedad de análisis (morfométricos, tafonómicos, traceológicos, experimentales, estadísticos, etc.) es el marco propuesto en este trabajo, para abordar el estudio de las industrias óseas musterienses y, por extensión, del Paleolítico inferior y medio.

\subsection{Los modelos de las incapacidades neandertales}

Por otro lado, las incapacidades cognitivas de los neandertales han sido un elemento importante en los paradigmas que explican su extinción, así como el paso del Paleolítico medio al superior.

Chase (1990) estudió una muestra de 32 huesos utilizados provenientes de La Quina, y determinó que eran retocadores. Sus conclusiones tienen cierto apoyo experimental, aunque con valor replicativo, para constatar la naturaleza de las huellas documentadas. Chase trata de demostrar que los retocadores de hueso son un útil de fortuna, utilizado de forma improvisada, y durante muy poco tiempo en cada caso, para el retoque de las raederas Quina y semi-Quina del yacimiento. El depósito estudiado, Locus 2, ha aportado una cantidad escasa de industria lítica (12 piezas retocadas, casi todas raederas Quina).

El enfoque propuesto por Chase enlaza con un planteamiento que presenta la variabilidad del utillaje musteriense como producto de la secuen- cia de talla y retoque de los útiles, sin que medie una voluntad de obtener unas morfologías concretas (Dibble 1989).

El trabajo de Dibble ha sido contestado con evidencias de planificación y complejidad en las tareas de producción y gestión del utillaje lítico en el Musteriense (Ríos Garaizar 2005; Airvaux y Soressi 2005; Soressi et al. 2002; Bourguignon 2001) y, en un reciente estudio, con nuevas pruebas sobre la eficacia y complejidad del utillaje en piedra del Paleolítico medio (Eren et al. 2008).

Por otra parte, no es correcto afirmar que las capacidades para realizar una industria ósea (o de cualquier otro tipo) con los rasgos del Paleolítico superior, no están presentes entre los neandertales. La capacidad de conformar el utillaje de acuerdo a unos rasgos preestablecidos, y la estandarización de la producción se ha constatado en yacimientos neandertales. En el Paleolítico medio, se ha probado en la producción lítica (Soressi et al. 2002; Soressi y D’Errico 2007). Para las últimas sociedades neandertales, se ha aportado la evidencia del trabajo de la industria ósea, al modo del Paleolítico superior, en el Chatelperroniense de la Grotte du Renne de Arcy-sur-Cure (3) (D'Errico et al. 2001; D'Errico 2003).

En cuanto al argumento de Chase, sobre los retocadores como útiles de fortuna, la evidencia de Axlor proporciona una imagen más completa que permite descartar ese carácter improvisado. Como se ha explicado, los soportes del nivel D muestran elementos de selección que pueden remontarse hasta el procesado de las diáfisis de las extremidades de ungulados (para la obtención de la médula).

Para su uso como retocadores se seleccionan esquirlas de huesos que provienen de unas partes anatómicas concretas (y no de otras que podrían parecer similares) y de unos taxones concretos. Esa selección se relaciona con la búsqueda de unas propiedades morfotécnicas del utillaje.

Por tanto, aunque sean útiles cuya vida tecnológica es breve (salvo algunas excepciones) la selección no es arbitraria ni casual. Aparecen posibles elementos de producción, ya que el origen de los soportes (taxón y parte anatómica) sugiere que la obtención de los soportes es un concepto

(3) Aunque White (2002) ha expresado reservas sobre la integridad de la secuencia, ésta fue considerada intacta por los excavadores originales (Leroi-Gourhan y Leroi-Gourhan 1964). 
presente en el momento de gestionar la fragmentación de las diáfisis óseas.

Estos elementos también contradicen la tesis defendida por Noble y Davidson (1996), que defiende la ausencia del concepto de "forma final" entre los neandertales, lo que les impediría, específicamente, realizar una industria ósea elaborada. La evidencia del nivel D de Axlor (selección de los soportes por criterios morfotécnicos, posible producción, integración del uso del hueso en otras tareas cotidianas) se suma a otras evidencias que contradicen dicha hipótesis. En especial, cabe destacar el conjunto de Paleolítico medio de Salzgitter-Lebenstedt, donde se ha detectado una cadena operativa compleja, con diversas técnicas para modificar la materia ósea y convertirla en útiles (Gaudzinski 1999). En este conjunto, de hecho, se hace evidente la capacidad de los Neandertales para trabajar una industria ósea "al modo del Paleolítico superior”. Para el Paleolítico superior inicial, ya se ha citado la evidencia, en ese sentido, del Chatelperroniense de la Grotte du Renne (D'Errico et al. 2001).

\section{CONCLUSIÓN}

El análisis de los retocadores de Axlor demuestra que es necesaria una profunda revisión del concepto de industria ósea utilizado en las investigaciones sobre el Paleolítico medio. Deben replantearse las técnicas de estudio del hueso, incluyendo el origen de la materia prima, sus características tecnológicas, y su dimensión funcional. La tafonomía, el análisis arqueozoológico, y el estudio de las propiedades físico-mecánicas del hueso se establecen como pilares fundamentales para el desarrollo metodológico. La cadena operativa se presenta como un método eficaz para integrar los resultados de los diferentes elementos de análisis.

Por otro lado, los rasgos de comportamiento (complejidad, planificación, integración del utillaje óseo en las actividades económicas, selección y conceptualización de formatos, rasgos morfotécnicos del utillaje) inferidos del presente estudio, son un argumento adicional (que se suma a otros más explícitos) contra los modelos de las incapacidades neandertales, tal y como fueron formulados por Stringer y Gamble (1993); Chase (1990); Dibble (1989); Noble y Davidson (1996) y Mellars (2004).

\section{BIBLIOGRAFÍA}

Alcántara, V.; Barba, R.; Barral del Pino, J.M.; Crespo, A.B.; Eiriz, A.I.; Falquina, A.; Herrero, S.; Ibarra, A.; Megías, M.; Pérez Gil, M.; Pérez Tello, V.; Rolland, J.; Yravedra, J.; Vidal, A. y Domínguez-Rodrigo, M. 2006: "Determinación de procesos de fractura sobre huesos frescos: un sistema de análisis de los ángulos de los planos de fracturación como discriminador de agentes bióticos". Trabajos de Prehistoria 63 (1): 37-45.

Altuna, J.; Baldeón, A. y Mariezkurrena, R. 1990: La cueva de Amalda (País Vasco) ocupaciones paleolíticas y postpaleolíticas. Sociedad de estudios vascos serie B4. Eusko Ikaskuntza. San Sebastián.

Anzidei, A.P. 2001: "Tools from elephant bones at La Polledrara di Cecanibbio and Rebibbia-Casal de' Pazzi”. En G. Cavarretta, P. Gioia, M. Mussi y M.R. Palombo (eds.): La terra degli Elefanti. Actas del 1. ${ }^{\circ}$ Congreso Internacional. Roma 2001: 415418. Roma.

Airvaux, J. y Soressi, M. 2005: "Nouvelles observations sur le Moustérien final du site paléolithique de Chez-Pinaud à Jonzac". Préhistoire du SudOuest 12: 163-174.

Armand, D. y Delagnes, A. 1998: "Les retouchoirs en os d'Artenac (couche 6c): perspectivas archéozoologiques taphonomiques et expérimentales". XVIII Rencontres internationales d'archéologie et d'histoire d'Antibes, 1997; Économie préhistorique: les comportements de subsistance au Paléolithique. Antibes 23-25 octubre 1997: 205-214. Antibes.

Baldeón, M. 1999: "El abrigo de Axlor (Bizkaia, País Vasco): Las industria líticas de sus niveles Musterienses". Munibe Antropologia-Arkeologia 51: 9-121.

Barandiarán, I. 1987: "Manipulación y uso de restos óseos". En P. Utrilla (ed.): La Cueva de Peña Miel, Nieva de Carneros, La Rioja. Excavaciones Arqueológicas en España 164. Ministerio de Cultura. Madrid: 87-101.

Barandiarán, J.M. 1980: "Excavaciones en Axlor". Obras Completas t.17 La Gran Enciclopedia Vasca. Bilbao.

Beauval, C. 2004: "La faune des niveaux mousteriens de "Chez-Pinaud" (Jonzac, Charente-Maritime, France. Prémiere analyse". Prehistorie du SudOuest Supplément 8: 125-156.

Bermúdez de Castro, J.M. y Sáenz de Buruaga, A. 1999: "Étude préliminaire du site pleistocène supérieur à hominidé d'Arrillor (Pays Basque, Espagne)". L'Anthropologie 103 (4): 633-639.

Binford, L. 1983: "Reply to Freeman". Current Anthropology 24: 372-376.

Blumenschine, R.J.; Marean, C.W. y Capaldo, S.D. 1996: "Blind Tests of Inter-analyst Correspondence and Accuracy in the Identification of Cut Marks, 
Percussion Marks, and Carnivore Tooth Marks on Bone Surfaces". Journal of Archaeological Science 23 (4): 493-507.

Boeda, E.; Bourguignon, L. y Griggo, C. 1998: “Activités de subsistance dans la couche VI3 b' (Moustérien) du gisement d'Umm El Tlel (Syrie)". En Économie préhistorique: les comportements de subsistance au Paléolithique. XIIIe rencontre internationale d'archéologie et d'histoire d'Antibes, Juan-les Pins, 23 au 25 octobre 1997: 243-258. Sophia Antipolis.

Bourguignon, L. 2001: “Apports de l'experimentation et de l'analyse techno-morfo-fonctionelle à la reconnaisance de processus d'amenagement de la retouche Quina". Préhistoire et approche expérimentale; Prehistoire 5: 35-66.

Capaldo, S.D. y Blumenschine, R.J. 1994: “Quantitative diagnosis of notches made by hammerstone percussion and carnivore gnawing on bovid long bones". American Antiquity 59 (4): 724-748.

Castaños, P. 2005: "Revisión actualizada de las faunas de macromamiferos del Würm antiguo en la Región Cantábrica". En R. Montes y J.A. Lasheras (eds.): Neandertales Cantábricos. Estado de la cuestión. Museo de Altamira, Monografías 20. Ministerio de Cultura. Madrid: 201-207.

Cruz-Uribe, K. y Klein, R.G. 1994. "Chew marks and cut marks on animal bones from the Kasteelberg B and Dune Field Midden Later Stone Age sites, Western Cape Province, South Africa". Journal of Archaeological Science 21 (1): 35-49.

Chase, P.G. 1990: "Tool-making tools and middle Paleolithic behaviour". Current Anthropology 31: 443-447.

D'Errico, F. 2003: "The Invisible Frontier. A Multiple Species Model for the Origin of Behavioral Modernity". Evolutionary Anthropology 12 (4): 188-202.

D’Errico, F.; Julien, M.; Liolios, D.; Baffier, D. y Anhaeren, M. 2001: "Les poinçons en os des couches châtelperroniennes et aurignaciennes de la grotte du Renne (Arcy-sur-Cure, Yonne): comparaisons technologiques, fonctionnelles et décor". Approches fonctionnelles en préhistoire. Actes du XXVe Congrès préhistorique de France, Nanterre, 24-26 novembre 2000: 45-66. Paris.

Díez Fernández-Lomana, J.C. y Navazo, M. 2005: "Apuntes sociales y geográficos a partir de los yacimientos del Paleolítico Medio en la zona nororiental de la Meseta castellano leonesa". En R. Montes y J.A. Lasheras (eds.): Neandertales Cantábricos. Estado de la cuestión. Museo de Altamira, Monografías 20. Ministerio de Cultura. Madrid: 39-54.

Dibble, H. 1989: "The implication of stonetool types for the presence of language during the lower and middle palaeolithic". En P. Mellars y C. Stringer (eds.): The human revolution. Cambridge University Press. Cambridge: 415-432.

Domínguez-Rodrigo, M. 1994: "Las acumulaciones óseas de macrofauna: revisión de los criterios de discernimiento de los agentes biológicos no antrópicos desde un enfoque ecológico". Zephyrus 46: 103-122.

Eren, M.I.; Greenspan, A. y Sampson, C.G. 2008: "Are Upper Paleolithic blade cores more productive than Middle Paleolithic discoidal cores? A replication experiment". Journal of Human Evolution 55 (6): 952-961.

Fisher, J.W. 1995: "Bone surface modifications in zooarchaeology". Journal of Archaeological Method and Theory 2 (1): 7-68.

Freeman, L.G. 1971: "Los niveles de ocupación musteriense". En J. González Echegaray y L.G. Freeman (eds.): Cueva Morín. Publicaciones del Patronato de las cuevas prehistóricas de la provincia de Santander VI. Santander: 27-161.

Gaudzinski, S. 1999: "Middle Palaeolithic bone tools from the open-air site Salzgitter-Lebenstedt (Germany)". Journal of Archaeological Science 26 (2): 125-141.

González Urquijo, J.; Ibáñez Estévez, J.J.; Ríos Garaizar, J.; Bourguignon, L.; Castaños, P. y Tarriño, A. 2005: "Excavaciones recientes en Axlor. Movilidad y planificación de actividades en grupos de neandertales". En R. Montes y J.A. Lasheras (eds.): Neandertales Cantábricos. Estado de la cuestión. Museo de Altamira, Monografías 20. Ministerio de Cultura. Madrid: 527-539.

Greenfield, H.J. 2006: "Slicing cut marks on animal bones: diagnostics for identifying stone tool type and raw materia". Journal of Field Archaeology 31: 147-163.

Henshilwood, C.S.; D’Errico, F.; Marean, C.M.; Milo, R.G. y Yates, R. 2001: "An early bone tool industry from the Middle Stone Age at Blombos Cave, South Africa: implications for the origins of modern human behaviour, symbolism and Language". Journal of Human Evolution 41: 631-678.

Leroi-Gourhan, A. y Leroi-Gourhan, A. 1964: "Chronologie des grottes d'Arcy-sur-Cure (Yonne, France)". Gallia Préhistoire 7: 1-64.

Leroy-Prost, C. 1974: "L'industrie osseuse aurignacienne de la collection Passemard d'Isturizt (Pyrénées-Atlantiques)". L'Anthropologie 78: 283-297.

Lyman, R. L. 1994: Vertebrate taphonomy. Cambridge University Press. Cambridge.

Martínez-Moreno, J. 2005/2006: "Las industrias en hueso 'poco elaboradas' de Lexetxiki y Axlor". Munibe: Antropología y arqueología: Homenaje a Jesús Altuna: 83-92.

Mellars, P. 2004: "Neanderthals and the modern human colonization of Europe". Nature 432 (7016): 461-465. 
Noble, W. y Davidson, I. 1996: Human Evolution, Language, and Mind: A Psychological and Archaeological Inquiry. Cambridge University Press. Cambridge.

Olsen, S. L. y Shipman P. 1988: "Surface modification on bone: Trampling versus butchery". Journal of Archaeological Science 15 (5): 535-553.

Outram, A. 2001: "A new approach to identifying bone marrow and grease explotation: Why the 'Indeterminate'. Fragments should not be ignored". Journal of Archaeological Science 28 (4): 401-410.

Outram, A. 2002: "Bone fracture and within-bone nutrients: An experimentally based method for investigating levels of marrow extraction. En P. Miracle y N. Milner (eds.): Consuming Passions and Patterns of Consumption. McDonald Institute for Archaeological Research. Cambridge: 51-64.

Passemard, E. 1922: "La Caverne d'Isturitz (Basses-Pyrénées)". Revue Archéologique 15: 1-45.

Passemard, E. 1924: Les Stations Paléolithiques du Pays Basque et leurs relations avec les Terrasses d'Alluvions de la Nive. Bodiou. Bayona.

Patou-Mathis, M. 1999: "Les outils osseux du Paléolithique inférieur et moyen en Europe. Problèmes, méthodes et résultats préliminaires". En Collectif (ed.): Préhistoire d'os. Recueil d'études sur l'industrie osseuse préhistorique offert à Henriette Camps-Fabrer. Publications de l'Université de Provence. Aix-en-Provence: 49-57.

Patou-Mathis, M. 2002: Fiches typologiques de l'industrie osseouse préhistorique. Cahier X: Retouchoirs, compresseurs, percuteurs. Os à impressions et à eraillures. Société Préhistorique Francaise. Paris.

Ríos Garaizar, J. 2005: “Características de la producción lítica al final del Paleolítico medio en el País Vasco. El caso del Nivel B de Axlor (Dima, Bizkaia)". En R. Montes y J.A. Lasheras (eds.): Neandertales Cantábricos. Estado de la cuestión. Mu- seo de Altamira, Monografías 20. Ministerio de Cultura, Madrid: 333-348.

Sanguino, J. y Montes, R. 2005: "Nuevos datos para el conocimiento del Paleolítico Medio en el centro de la Región Cantábrica: la Cueva de Covalejos (Piélagos, Cantabria)". En R. Montes y J.A. Lasheras (eds.): Neandertales Cantábricos. Estado de la cuestión. Museo de Altamira, Monografías 20. Ministerio de Cultura, Madrid: 489-504.

Soressi, M.; Armand, D.; D’Errico, F.; Jones, H.L.; Pubert, E.; Rink, W.J.; Texier, J.-P. y Vivent, D. 2002: "Pech de l'Azé I (Carsac, Dordogne): nouveaux travaux de recherche sur le Moustérien de tradition acheuléenne". Bulletin de la Société préhistorique Française 99: 5-11.

Soressi, M. y D’Errico, F. 2007: 'Pigments, gravures, parures: les comportements symboliques controversés des néandertaliens". Les Néandertaliens. Biologie et cultures. Éditions du CTHS (Documents préhistoriques 23). Paris: 297-309.

Straus, L.G. 1992: Iberia Before the Iberians. The Stone Age Prehistory of Cantabrian Spain. University of New Mexico Press. Alburquerque.

Stringer, C. y Gamble, C. 1993: In search of Neanderthals: Solving the puzzle of Human Origins. Thames and Hudson. Londres.

Tinnes, J. 2001: "Die retuscheure aus Knochen der Magdalénien-Fundplätze Gönnersdorf und Andernach". Zeit-Räume, Gedenkschrift für Wolfgang Taute. Deutsche Gesellschaft für Ur- und Frühgeschichte. Bonn: 337-347.

Valensi, P. 1996: "Taphonomie des grands mamifères et palethnologie á la grotte du Lazaret (Nice, France)". Anthropozoologica 3: 13-28.

White, R. 2002: "Observations technologiques sur les objets de parure". En B. Schmider (ed.): L'Aurignacien de la grotte de Renne: Les fouilles d'André Leroi-Gourhan à Arcy-sur-Cure (Yonne). XXXIVe Supplément à Gallia Préhistoire: 257-266. 